\title{
EVIDENCE FOR A MALE-PRODUCED SEX PHEROMONE IN THE WESTERN FLOWER THRIPS Frankliniella occidentalis
}

\author{
WILLIAM D. J. KIRK ${ }^{1, *}$ and JAMES G. C. HAMILTON ${ }^{1}$ \\ ${ }^{1}$ Centre for Applied Entomology and Parasitology, School of Life Sciences \\ Keele University, Staffordshire ST5 5BG, United Kingdom
}

(Received August 1, 2003; accepted September 21, 2003)

\begin{abstract}
Olfactometer bioassays of walking adult western flower thrips Frankliniella occidentalis (Pergande) (Thysanoptera: Thripidae) showed that virgin females (1- to 3-d postemergence) were attracted to the odor of 25 adult males, but not to the odor of 25 adult females, providing behavioral evidence for a male-produced sex pheromone in this species. In contrast to earlier findings, mixed-age adult males were attracted to the odor of adult males. GC analysis of odors collected on SPME fibers revealed two major components and five minor components that were present in the male odor and not in the female odor. The compounds were not present in hexane extracts of males, indicating that these compounds are produced on demand and not stored.
\end{abstract}

Key Words-Frankliniella occidentalis, Thysanoptera, Thripidae, sex pheromone, mating, aggregation, sternal gland, olfactometer, integrated pest management.

\section{INTRODUCTION}

In many species of thrips, including the western flower thrips Frankliniella occidentalis (Pergande) (Thysanoptera: Thripidae), adult males possess a series of abdominal "sternal glands," which are structurally consistent with pheromone release (Bode, 1978; Moritz, 1997). Circumstantial evidence suggests that the glands produce a sex pheromone that calms females at very close range (Pelikan, 1951). However, the discovery that adult female Frankliniella schultzei respond when walking or in flight to the odor of adult males provides evidence for an attractant role (Milne, 1997; Milne et al., 2002). de Kogel and van Deventer (2003) have since provided behavioral evidence for a male-produced sex pheromone in $F$. occidentalis that attracts females but not males. This species forms male

*To whom correspondence should be addressed. E-mail: w.d.j.kirk@keele.ac.uk 
aggregations, within which there are aggressive male-male interactions and females arrive, mate, and leave immediately (Terry and Gardner, 1990; Terry and Dyreson, 1996; Terry, 1997). A male-produced sex pheromone could have many roles in the complex interactions within and between the sexes at aggregation sites.

No information on the chemical identity of a sex pheromone has yet been published for any species of thrips (Terry, 1997), although anal secretions have been identified in many species (Suzuki et al., 2000). In F. occidentalis, the larvae, but not adults, produce an anal droplet consisting of decyl acetate and dodecyl acetate, which acts as an alarm pheromone and has many effects on the behavior of both larvae and adults (Teerling et al., 1993; MacDonald et al., 2002, 2003).

This paper confirms and extends the behavioral evidence for a male-produced sex attractant pheromone in $F$. occidentalis and provides chemical evidence of male-produced volatiles that are possible pheromone components. A synthetic sex pheromone could improve the monitoring or integrated pest management of this species, which has spread since the 1970 s to become a major worldwide pest of horticulture and agriculture (Kirk, 2002; Kirk and Terry, 2003).

\section{METHODS AND MATERIALS}

Thrips Rearing. A culture of F. occidentalis from commercial glasshouses in the United Kingdom was maintained on pot chrysanthemums (Dendranthema grandiflora Tzvelev) at $25 \pm 2^{\circ} \mathrm{C}$ and L18:D6. Adult thrips collected arbitrarily from this culture are described as "mixed age." To obtain known-age virgin females, adults were transferred from the chrysanthemums to 500-ml plastic pots (Nalgene, Nalge Ltd., UK) containing French bean pods (Phaseolus vulgaris L.) and pine pollen (Pinus brutia Tenore) and kept at $25 \pm 0.3^{\circ} \mathrm{C}$ and L18:D6. A hole (diam. 70 $\mathrm{mm}$ ) in the lid allowed moisture exchange through a piece of tissue (Kimwipes Lite, Kimberley-Clark, U.K.) held in place between the lid and the pot. The resulting second-instars were isolated, to prevent later mating, by moving them to individual Eppendorf tubes containing a section of bean pod sealed with paraffin wax at each end. A hole in the lid (diam. $5 \mathrm{~mm}$ ) allowed moisture exchange through a piece of tissue between the lid and the tube. Daily observations of the tubes allowed the day of adult emergence to be recorded.

Y-Tube Olfactometer. A glass Y-tube with branches at an angle of $90^{\circ}$ and stem and branches of length $60 \mathrm{~mm}$ and internal diam $5 \mathrm{~mm}$ was held horizontally. Zero-grade air from a cylinder (British Oxygen Corporation, Manchester) was passed through an activated charcoal filter, separated into two streams, and then flow-rate regulated by two rotameters (Supelco, U.K.) to a speed of $50 \mathrm{~mm} \mathrm{sec}^{-1}$ in each branch of the Y-tube and $100 \mathrm{~mm} \mathrm{sec}^{-1}$ in the stem. A 50-ml round glass flask with a Drechsel head before each branch of the Y-tube provided test and control odor sources. Small pieces of glass wool in the inlet and outlet tubes prevented 
thrips leaving the flask. Each flask had a semicircle of filter paper (Whatman No. 1, diam. $42.5 \mathrm{~mm}$ ), kept moistened with distilled water inside it, and was illuminated from above by four fluorescent tubes and one arm of a fiber-optic cold light source at a distance of $40 \mathrm{~mm}$ (about 10,000 lux). These conditions were used because they produced the patrolling and fighting behavior shown by males at aggregations (Terry and Gardner, 1990), which was considered most likely to induce pheromone production. Thrips remained active for at least $6 \mathrm{hr}$. Connections were made with Teflon tubing and brass Swagelok connectors. The Y-tube was screened on all sides from visual influences by a 100 -mm high wall of matt black card and illuminated from above by four fluorescent tubes (about 1900 lux). A similar Y-tube olfactometer system worked well for assessing the responses of F. occidentalis to volatile plant compounds (Koschier et al., 2000).

Bioassays. Experiments were carried out at $25 \pm 1{ }^{\circ} \mathrm{C}$. Odor-source thrips (25 mixed-age adults) were collected with a small aspirator, anesthetized briefly with carbon dioxide, checked for gender under a dissecting microscope, then counted into the treatment flask. Test thrips were transferred individually from plants to the base of the Y-tube with an aspirator and a fine brush and were not anesthetized. They walked up the tube and a "choice" was recorded when they crossed a line $20 \mathrm{~mm}$ down either branch. "No choice" was recorded if the line had not been crossed after 3 min for females or, because they took longer to run, 4 min for males. After a "choice" or a "no choice," each thrips was removed from the tube and placed at the base of the Y-tube again to be allowed to make a second choice. After every five or six thrips, the flasks, tubing, and Y-tube were turned $180^{\circ}$ to reverse sides and minimize any side bias. About 20-30 individuals were tested in each run of an experiment. The apparatus was cleaned thoroughly before each run by rinsing with hexane. The glassware was also baked overnight at $200^{\circ} \mathrm{C}$. Each experiment consisted of two or three runs.

Data Analysis. The bioassay data were analyzed with SPSS 11 (SPSS Inc., Chicago, Illinois, USA). "No choices" were excluded from the analysis. Data for first and second choices and for runs within an experiment were homogeneous $(P>0.05)$ in all cases and were combined. This was tested by a chi-square test with exact $P$ values valid for small sample sizes. Responses were tested by a binomial test with exact two-tailed $P$ values, with the null hypothesis that the two arms were chosen with equal probability.

Collection and Analysis of Volatiles. Mixed-age adult males or females were collected as described above for odor-source thrips and moved to a small glass flask sealed with a piece of Teflon tape. They were kept at $25-30^{\circ} \mathrm{C}$ and illuminated similarly to those in the bioassay so as to induce patrolling and fighting behavior. Headspace volatiles were collected on a 20-mm long 50/30 $\mu \mathrm{m}$ DVB/Carboxen SPME fiber assembly (57348-U, Supelco, U.K.). Collections were made for 4-5 hr from approximately 30-60 male or female thrips and repeated 10 times for males 
and 5 times for females. Analyses of headspace volatiles collected from male or female thrips were preceded by analysis of headspace volatiles from the apparatus without the presence of thrips (blank control). SPME fibers were pre conditioned by heating to $180^{\circ} \mathrm{C}$ for $2 \mathrm{hr}$ before use. In addition, hexane extracts from five to hundreds of males were obtained by collecting males directly from chrysanthemum plants. Males were immersed in hexane and stored at $-20^{\circ} \mathrm{C}$ until analysis.

Anal droplets were collected directly on SPME fibers from five second-instars to provide comparative retention time data for decyl acetate and dodecyl acetate, the components of the larval alarm pheromone (Teerling et al., 1993).

SPME samples and hexane extracts were analyzed on an Hewlett-Packard $5890 \mathrm{II}+$ gas chromatograph with an HP-5 capillary column, $30 \mathrm{~m} \times 0.25 \mathrm{~mm}$ i.d., $0.25-\mathrm{mm}$ film thickness. The sample was introduced via a septum-less heated injector $\left(180^{\circ} \mathrm{C}\right)$ and the gas chromatograph (GC) was temperature programmed with an initial $2 \mathrm{~min}$ at $40^{\circ} \mathrm{C}$, then an increase of $10^{\circ} \mathrm{C} \mathrm{min}^{-1}$ to a final isothermal period at $250^{\circ} \mathrm{C}(10 \mathrm{~min})$.

\section{RESULTS}

Bioassays. Virgin females (1- to 3-d postemergence) were attracted to the odor of 25 adult males, but not to the odor of 25 adult females (Table 1). Mixedage adult females were also attracted to adult males and their preference for the odor side $(66 \%)$ was similar to that of virgin females $(70 \%)$. However, the response was not exclusively by females to males, because mixed-age males were also attracted to adult male odors. The preference of mixed-age adult males for males $(66 \%)$ was similar to that of females for males.

Each thrips was tested twice in succession. For the odor sources that were preferred, there was no significant difference in preference between the first and

TABLE 1. RESPONSES OF WALKING AdULT Frankliniella occidentalis TO OTHER Adults of The SAme Species in a Y-Tube Olfactometer Bioassay ${ }^{a}$

\begin{tabular}{|c|c|c|c|c|c|}
\hline \multirow[b]{2}{*}{ Test insects ${ }^{b}$} & \multirow{2}{*}{$\begin{array}{c}\text { Odor } \\
\text { source }^{c}\end{array}$} & \multicolumn{2}{|c|}{ Number of choices } & \multirow{2}{*}{$\begin{array}{c}\text { Preference for } \\
\text { odor side } \%\end{array}$} & \multirow[b]{2}{*}{ Probability } \\
\hline & & Odor side & Control side & & \\
\hline Virgin females & Males & 69 & 29 & 70 & $<0.001$ \\
\hline Virgin females & Females & 44 & 62 & 42 & 0.10 \\
\hline Females & Males & 60 & 31 & 66 & 0.003 \\
\hline Males & Males & 65 & 34 & 66 & 0.002 \\
\hline
\end{tabular}

${ }^{a}$ Significance levels based on null hypothesis of equal preference for the two sides.

${ }^{b}$ All test insects were adults. Virgin females were 1- to 3-d postemergence and others were of mixed age.

${ }^{c}$ All odor sources consisted of 25 live adults of mixed age. 
second choices $(P>0.05$ for each experiment and each run of each experiment), indicating that responses occurred quickly, within minutes of encountering the odor, and were not improved by several minutes of additional prior exposure. There was also no significant correlation between the first and second choices of individual thrips for virgin females tested with odor from males $(P=0.72)$, mixed-age females tested with odor from males $(P=0.49)$ or males tested with odor from males $(P=0.73)$. Thus, thrips that chose the test odor as their first choice were not more likely to choose it as their second choice than thrips that had chosen the control odor as first choice.

Analysis of Volatiles. Comparison of the GC traces from male (upper trace) and female (lower trace) SPME volatile collections (Figure 1) revealed two major peaks in the male trace that were absent from the trace of female volatiles: peak $a$ $\left(t_{\mathrm{R}}=11.45 \mathrm{~min}\right.$; abundance $=19.6 \%$ by peak area of male-exclusive compounds $)$ and peak $b\left(t_{\mathrm{R}}=15.11 \mathrm{~min} ; 67.1 \%\right)$. Comparison of these retention times with those of the larval anal droplet compounds $\left(t_{\mathrm{R}}=13.04 \mathrm{~min}\right.$ for decyl acetate; $t_{\mathrm{R}}=15.45 \mathrm{~min}$ for dodecyl acetate) indicated that they were not the same compounds and could not be the result of contamination with alarm pheromone. Other peaks found in very small amounts in most of the male traces that appeared to be absent from all the female traces were found at $t_{\mathrm{R}}=7.61 \mathrm{~min}, 4.2 \% ; 7.71 \mathrm{~min}$, $0.9 \%$; $7.88 \mathrm{~min}, 4.1 \%$; $10.61 \mathrm{~min}, 1.9 \%$; and $10.97 \mathrm{~min}, 2.3 \%$. The release rate of compound $a$ was estimated to be $120 \mathrm{pg} \mathrm{male}^{-1} \mathrm{hr}^{-1}$, by comparison of the peak

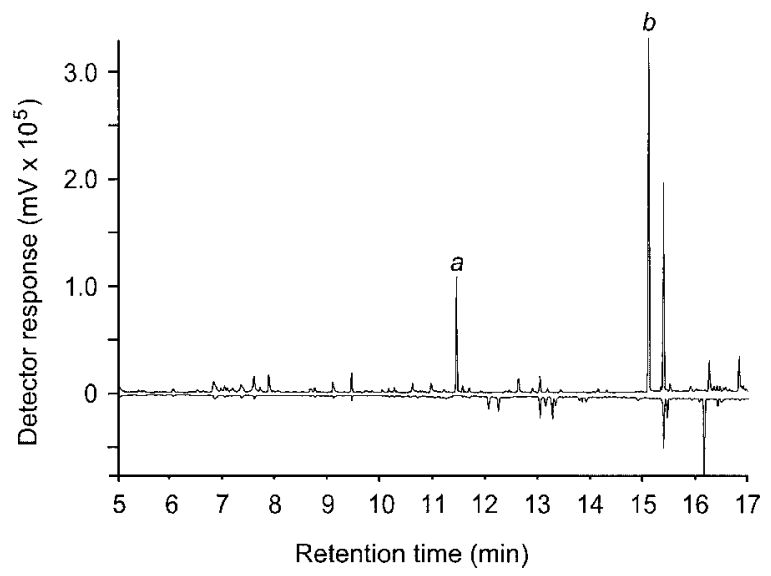

FIG. 1. GC traces of SPME fiber collections of the headspace volatiles collected from mixed-age adult males (upper trace) and mixed-age adult females (inverted lower trace) of Frankliniella occidentalis. The major male-specific compounds in the male trace are indicated as peaks $a$ and $b$. 
area of the unknown with a hydrocarbon standard. The compounds were not found in hexane extracts of males.

\section{DISCUSSION}

The results confirm that females in a Y-tube olfactometer are attracted to the odor of males but not to the odor of females, as found by de Kogel and van Deventer (2003), and extend the results to virgin females. The olfactometer preference shown here by virgin females and mixed-age females for 25 males $(66-70 \%)$ was similar to that of females for 20 or 80 males $(68-71 \%)$ found by de Kogel and van Deventer (2003). Because adult females can mate within hours of emergence (Terry and Schneider, 1993) and there were many males in the culture, most mixed-age females were likely to have mated. This suggests that the response of females to male odor is not specific to virgins, although this needs to be verified experimentally.

Males were attracted to males, contrary to the findings of de Kogel and van Deventer (2003) for F. occidentalis and Milne et al. (2002) for F. schultzei. The difference may be because the males in our bioassay were patrolling and fighting, which may affect pheromone production. The entrainment of male-specific volatiles from patrolling and fighting males and the absence of these volatiles from hexane extracts of males collected directly from plants also supports this explanation.

Although the bioassay tested the responses of walking thrips, a flight response is also likely because this would be biologically advantageous for locating aggregation sites and because a flight response by females to males has been shown in another species from the same genus (Milne et al., 2002).

The sternal glands are the most likely source of a male pheromone, but this cannot be verified by dissecting males and comparing extracts from parts of the body because the male-specific compounds appear not to be stored. Abdominal sternal glands or ventral glands occur on adult males in some other insects, such as some true bugs (Schuh and Slater, 1995) and some cockroaches (Sreng, 1984). In the cockroach Nauphoeta cinerea, 12 male-specific compounds have been identified from the sternal glands, of which three are the principal active components in the pheromone (Sreng, 1990; Sirugue et al., 1992). Between them, these compounds have roles in attracting females from a distance and in close-range interactions with females and males (Moore, 1997). A male-produced pheromone may also have several behavioral roles in F. occidentalis.

The identification of the seven volatile compounds from male $F$. occidentalis is in progress.

Acknowledgments - The research was partly supported by Novartis BCM (now Syngenta Bioline). We thank Emma Wilkins and Vickie Carter for technical assistance with these experiments and pilot experiments from July 1998 to December 2002. 


\section{REFERENCES}

BODE, W. 1978. Ultrastructure of the sternal glands in Thrips validus Uzel (Thysanoptera, Terebrantia). Zoomorphologie 90:53-65.

DE Kogel, W. J. and VAn DeVEnTER, P. 2003. Intraspecific attraction in the western flower thrips, Frankliniella occidentalis; indications for a male sex pheromone. Entomol. Exp. Appl. 107:8789.

KIRK, W. D. J. 2002. The pest and vector from the West: Frankliniella occidentalis, pp. 33-44, in R. Marullo and L. A. Mound (eds.). Thrips and Tospoviruses: Proceedings of the 7th International Symposium on Thysanoptera. Australian National Insect Collection, Canberra.

KIRK, W. D. J. and TERRY, L. I. 2003. The spread of the western flower thrips Frankliniella occidentalis (Pergande). Agric. Forest Entomol. 5:301-310.

Koschier, E. H., De Kogel, W. J., and Visser, J. H. 2000. Assessing the attractiveness of volatile plant compounds to western flower thrips Frankliniella occidentalis. J. Chem. Ecol. 26:26432655.

Macdonald, K. M., Hamilton, J. G. C., Jacobson, R., and KiRK, W. D. J. 2002. Effects of alarm pheromone on landing and take-off by adult western flower thrips. Entomol. Exp. Appl. 103:279282.

Macdonald, K. M., Hamilton, J. G. C., Jacobson, R., and KiRK, W. D. J. 2003. Analysis of anal droplets of the western flower thrips Frankliniella occidentalis. J. Chem. Ecol. 29:2385-2389.

MiLnE, M. 1997. Host plant relationships and significance of prey in the diet of two phytophagous thrips species, Frankliniella schultzei and Thrips tabaci (Thysanoptera: Thripidae). PhD Dissertation, University of Queensland, Brisbane, Australia.

Milne, M., Walter, G. H., and Milne, J. R. 2002. Mating aggregations and mating success in the flower thrips, Frankliniella schultzei (Thysanoptera: Thripidae), and a possible role for pheromones. J. Insect Behav. 15:351-368.

MoORE, A. J. 1997. The evolution of social signals: Morphological, functional, and genetic integration of the sex pheromone in Nauphoeta cinerea. Evolution 51:1920-1928.

MoriTZ, G. 1997. Structure, growth and development, pp. 15-63, in T. Lewis (ed.). Thrips as Crop Pests. CAB International, Wallingford, UK.

PELIKAN, J. 1951. On carnation thrips Taeniothrips dianthi Priesner [In Czech]. Ent. Listy 14:5-38.

SchuH, R. T. and Slater, J. A. 1995. True Bugs of the World (Hemiptera: Heteroptera). Cornell University Press, Ithaca, NY.

Sirugue, D., Bonnard, O., Le Quere, J.-L., Farine, J.-P., and Brossut, R. 1992. 2-Methylthiazolidine and 4-ethylguaiacol, male sex pheromone components of the cockroach Nauphoeta cinerea (Dictyoptera, Blaberidae): A reinvestigation. J. Chem. Ecol. 18:2261-2276.

SRENG, L. 1984. Morphology of the sternal and tergal glands producing the sexual pheromones and the aphrodisiacs among the cockroaches of the subfamily Oxyhaloinae. J. Morphol. 182:279-294.

SRENG, L. 1990. Seducin male sex pheromone of the cockroach Nauphoeta cinerea: Isolation, identification, and bioassay. J. Chem. Ecol. 16:2899-2912.

SuzuKi, T., Haga, K., Tsutsumi, T., and Matsuyama, S. 2000. Chemical analysis and comparison of acid components of anal secretions of idolothripine thrips. J. Chem. Ecol. 26:2449-2458.

Teerling, C. R., Pierce, H. D., Jr., Borden, J. H., and Gillespie, D. R. 1993. Identification and bioactivity of alarm pheromone in the western flower thrips, Frankliniella occidentalis. J. Chem. Ecol. 19:681-697.

TERRY, L. I. 1997. Host selection, communication and reproductive behavior, pp. 65-118, in T. Lewis (ed.). Thrips as Crop Pests. CAB International, Wallingford, UK.

TERRY, L. I. and DYRESON, E. 1996. Behavior of Frankliniella occidentalis (Thysanoptera: Thripidae) within aggregations, and morphometric correlates of fighting. Ann. Entomol. Soc. Am. 89:589602 . 
TERRY, L. I. and GARDNER, D. 1990. Male mating swarms in Frankliniella occidentalis (Pergande) (Thysanoptera: Thripidae). J. Insect Behav. 3:133-141.

TERRY, I. and SCHNEIDER, M. 1993. Copulatory behavior and mating frequency of the western flower thrips, Frankliniella occidentalis (Insecta: Thysanoptera). J. Pure Appl. Zool. 4:339354. 